\title{
Erratum to: Conflict of interest declaration
}

\author{
Mark Oremus $\cdot$ Andrew Don-Wauchope $\cdot$ Robert McKelvie $\cdot$ Pasqualina L. Santaguida \\ Stephen Hill - Cynthia Balion - Ronald Booth · Judy A. Brown - Usman Ali • \\ Amy Bustamam $\cdot$ Nazmul Sohel $\cdot$ Parminder Raina
}

Published online: 9 August 2014

(C) Springer Science+Business Media New York 2014

\section{Erratum to: Heart Fail Rev \\ DOI 10.1007/s10741-014-9439-6 \\ DOI 10.1007/s10741-014-9440-0 \\ DOI 10.1007/s10741-014-9445-8 \\ DOI 10.1007/s10741-014-9447-6}

The conflict of interest declaration for these four articles (for which the author group is same) should read as follows.
Conflict of interest Mark Oremus, Robert McKelvie, Pasqualina L.
Santaguida, Usman Ali, Cynthia Balion, Stephen Hill, Judy A.
Brown, Amy Bustamam, Nazmul Sohel, and Parminder Raina have
no conflicts of interest or financial ties to disclose. Andrew C. Don-
Wauchope has received clinical trial support from AMGEN. Ronald
A. Booth has received honoraria from INOVA Diagnostics Inc. and is
a member of the Health Technology Expert Review Panel of the
Canadian Agency for Drugs and Technologies in Health (CADTH).

The online version of the original articles can be found under DOIs:10.1007/s10741-014-9447-6, 10.1007/s10741-014-9445-8, 10. 1007/s10741-014-9440-0, 10.1007/s10741-014-9439-6.

M. Oremus · P. L. Santaguida - J. A. Brown · U. Ali ·

A. Bustamam · N. Sohel · P. Raina $(\square)$

Department of Clinical Epidemiology and Biostatistics,

McMaster University, 1280 Main Street West, MIP Suite 309A,

Hamilton, ON L8S 4K1, Canada

e-mail: praina@mcmaster.ca

A. Don-Wauchope $\cdot$ S. Hill $\cdot$ C. Balion

Department of Pathology and Molecular Medicine, McMaster

University, Hamilton, ON, Canada

R. McKelvie

Department of Medicine, McMaster University, Hamilton, ON, Canada

R. Booth

Department of Pathology and Laboratory Medicine, University of Ottawa, Ottawa, ON, Canada 